\title{
Association of adiponectin with hepatic steatosis: a study of 1,349 subjects in a random population sample
}

\author{
Marion Flechtner-Mors ${ }^{1 \dagger}$, Samuel N George ${ }^{2 \dagger}$, Suemeyra Oeztuerk ${ }^{2}$, Mark M Haenle ${ }^{2}$, Wolfgang Koenig ${ }^{3}$, \\ Armin Imhof ${ }^{3}$, Bernhard O Boehm², Tilmann Graeter ${ }^{4}$, Richard A Mason ${ }^{5}$, Wolfgang Kratzer ${ }^{2 *}$, Atilla S Akinli ${ }^{2}$ \\ and the EMIL-Study group
}

\begin{abstract}
Background: Objective of the present study was to examine the association between adiponectin and hepatic steatosis, and other biochemical and anthropometric parameters in healthy subjects.

Results: A total of 1349 subjects (age 18-65 years) underwent ultrasound examination of the liver. Mean adiponectin concentration for the study collective was $11.35 \pm 6.28 \mu \mathrm{g} / \mathrm{mL}$. The following parameters were assessed for their association with adiponectin: body-mass index (BMI); age; sex; arterial blood pressure; nicotine use; alcohol consumption; physical activity; metabolic syndrome; total, low-density lipoprotein (LDL) and high-density lipoprotein (HDL) cholesterol; triglycerides; aspartate aminotransferase (AST); alanine aminotransferase (ALT); $y$-glutamyltransferase (GGT); alkaline phosphatase (AP); C-reactive protein (CRP); insulin sensitivity according to the Homeostasis Model Assessment (HOMA); random blood glucose; and the degree of steatosis of the liver. The numerical differences in the variables influencing adiponectin returned in the descriptive analysis were confirmed at bivariate analysis for BMI, ALT, AST, GGT, AP, total and HDL cholesterol, triglycerides, CRP, arterial blood pressure, metabolic syndrome, nicotine use and alcohol consumption. The logistic regression of the multivariate analysis showed that male sex, hepatic steatosis, BMI, metabolic syndrome, tobacco smoking and CRP correlate negatively with adiponectin, while age, moderate alcohol consumption and HDL cholesterol exhibit a positive association.
\end{abstract}

Conclusions: The results of the present study confirm the findings of previous research. Adiponectin correlates negatively with cardiometabolic risk factors and is an independent indicator for non-alcoholic fatty liver disease (NAFLD).

Keywords: Ultrasonography, Fatty liver, NAFLD, Adipose tissue, Cross-sectional studies

\section{Background}

Over the past several years, non-alcoholic fatty liver disease (NAFLD) has gained increasing importance, both as a clinical entity and as a focus of research [1]. NAFLD is characterized by an increased accumulation of fat in the hepatocytes in the absence of excessive alcohol consumption [2]. Its prevalence worldwide is estimated in the range of $20-30 \%$. NAFLD includes both non-alcohol fatty liver (NAFL), characterized by a simple increase in

\footnotetext{
* Correspondence: Wolfgang.Kratzer@uniklinik-ulm.de

'Equal contributors

${ }^{2}$ Department of Internal Medicine I, University Hospital UIm,

Albert-Einstein-Allee 23, Ulm 89081, Germany

Full list of author information is available at the end of the article
}

the fat content of the liver, and non-alcoholic steatohepatitis (NASH) with increased fat content and inflammatory infiltrates. About $10-20 \%$ of patients with NAFL develop $\mathrm{NASH}$, which may ultimately lead to cirrhosis of the liver and to hepatocellular carcinoma (HCC) [3-5].

While NAFLD is closely associated with obesity, type 2 diabetes mellitus and coronary artery disease (CAD), it may occur in the absence of type 2 diabetes and CAD [6,7]. The increased fat content of the liver correlates positively with the insulin resistance that characterizes metabolic syndrome [8]: hence, NAFLD is often considered an hepatic manifestation of metabolic syndrome [9]. It remains unclear, however, whether insulin resistance

\section{Biomed Central}

(c) 2014 Flechtner-Mors et al.; licensee BioMed Central Ltd. This is an Open Access article distributed under the terms of the Creative Commons Attribution License (http://creativecommons.org/licenses/by/2.0), which permits unrestricted use, distribution, and reproduction in any medium, provided the original work is properly credited. 
triggers an increase in the fat content of the liver or whether an increased fat content of the liver precedes the development of insulin resistance or causes insulin resistance per se [10]. It is known that adiponectin, a peptide hormone released from adipose tissue affects both the fat content of the liver and the development of NAFLD [11].

Unlike most adipose tissue hormones, adiponectin shows decreased concentrations in obesity and correlates negatively with both cardiometabolic risk factors and with the fat content of the liver [12,13]. Adiponectin concentrations are $20-60 \%$ lower in patients with NAFLD than in healthy persons [8]. There is evidence in the literature that adiponectin at sufficiently high concentrations may protect against the development of NAFL [14].

Objective of the present study was to analyze the association between adiponectin and cardiometabolic risk factors, and with sonographically diagnosed hepatic steatosis in a healthy population of a small German town.

\section{Results}

\section{Descriptive analysis}

The study collective consisted of 1,349 subjects (733 females, 54.3\%; 616 males, 45.7\%; mean age, $41.3 \pm$ 12.5 years). Among all subjects, $24.7 \%$ exhibited sonographic evidence of hepatic steatosis, $47.8 \%$ were overweight, $12.2 \%$ had a history of hypertension, $3.9 \%$ fulfilled the (modified) criteria for metabolic syndrome, $50.1 \%$ were current or former smokers, $87.3 \%$ reported no or very low consumption of alcohol, and $61.2 \%$ described engaging in physical exercise.

The mean plasma concentration of adiponectin in all 1,349 study subjects was $11.35 \pm 6.28 \mu \mathrm{g} / \mathrm{mL}$. The mean adiponectin concentrations of subjects broken down by age, degree of hepatic steatosis, BMI, metabolic syndrome, alcohol consumption and physical exercise are given in Table 1. Table 2 gives mean adiponectin concentrations of subjects broken down according to laboratory parameters that were within, above or below the respective reference ranges.

\section{Bivariate analysis}

There was a statistically significant negative correlation between the adiponectin concentration and BMI. The hepatic function (ALT, AST, GGT) and cholestasis parameters (AP) also correlated negatively with adiponectin. Among the lipids, triglycerides showed a negative correlation, while total cholesterol showed a weak positive correlation and HDL cholesterol a narrowly positive correlation. LDL cholesterol showed a negative correlation without, however, attaining statistical significance. Random blood glucose and insulin sensitivity (HOMA) also showed a negative correlation with adiponectin
Table 1 The concentration of adiponectin in 1,349 healthy subjects

\begin{tabular}{|c|c|c|}
\hline & $\mathbf{N}$ & Adiponectin $(\mu \mathrm{g} / \mathrm{ml})$ Mean $\pm \mathrm{SD}$ \\
\hline \multicolumn{3}{|l|}{ Sex } \\
\hline Females & 733 & $13,87 \pm 6,77$ \\
\hline Males & 616 & $8,34 \pm 3,89$ \\
\hline \multicolumn{3}{|l|}{ Age (years) } \\
\hline $18-30$ & 274 & $10,77 \pm, 44$ \\
\hline $31-40$ & 400 & $10,97 \pm 6,08$ \\
\hline $41-50$ & 312 & $11,22 \pm 6,34$ \\
\hline $51-65$ & 363 & $12,30 \pm 6,91$ \\
\hline \multicolumn{3}{|c|}{ Hepatic steatosis } \\
\hline Grad 0 & 1016 & $12,02 \pm 6,44$ \\
\hline Grad 1 & 153 & $10,27 \pm 6,07$ \\
\hline Grad 2/3 & 180 & $8,47 \pm 4,27$ \\
\hline \multicolumn{3}{|c|}{ Body Mass Index $\left(\mathrm{kg} / \mathrm{m}^{2}\right)$} \\
\hline$<25$ & 704 & $12,65 \pm 6,64$ \\
\hline $25-30$ & 437 & $10,14 \pm 5,61$ \\
\hline$>30$ & 208 & $9,48 \pm 5,30$ \\
\hline \multicolumn{3}{|l|}{ Hypertension } \\
\hline No & 1174 & $11,48 \pm 6,29$ \\
\hline Yes & 164 & $10,59 \pm 6,18$ \\
\hline Unknown & 11 & $8,30 \pm 4,96$ \\
\hline \multicolumn{3}{|c|}{ Metabolic syndrome } \\
\hline No & 1296 & $11,51 \pm 6,31$ \\
\hline Yes & 53 & $7,38 \pm 3,64$ \\
\hline \multicolumn{3}{|c|}{ Tobacco smoking } \\
\hline No & 672 & $12,16 \pm 6,76$ \\
\hline Yes & 385 & $10,34 \pm 5,85$ \\
\hline Former smoker & 292 & $10,81 \pm 5,35$ \\
\hline \multicolumn{3}{|l|}{ Alcohol } \\
\hline Ex-drinker & 40 & $9,78 \pm 5,51$ \\
\hline $0 \mathrm{~g}$ & 509 & $11,32 \pm 6,20$ \\
\hline $1-20 \mathrm{~g} / \mathrm{Tag}$ & 671 & $11,89 \pm 6,65$ \\
\hline $21-40 \mathrm{~g} / \mathrm{Tag}$ & 129 & $9,14 \pm 3,79$ \\
\hline \multicolumn{3}{|c|}{ Physical exercise } \\
\hline No & 523 & $11,19 \pm 6,52$ \\
\hline Yes & 826 & $11,44 \pm 6,12$ \\
\hline
\end{tabular}

$\mathrm{SD}=$ standard deviation.

concentrations, though likewise failing to achieve statistical significance (Table 3).

Hypertension, metabolic syndrome, hepatic steatosis and tobacco use showed a negative correlation with adiponectin $(p<0.0001)$. There was a positive correlation with age and alcohol consumption $(p<0.0001)$. There was no clear correlation between physical exercise and the adiponectin concentration $(p<0.3285)$. 
Table 2 Adiponectin concentration broken down according to laboratory parameters

\begin{tabular}{|c|c|c|}
\hline & $\mathrm{N}$ & Adiponectin $(\mu \mathrm{g} / \mathrm{ml})$ Mean $\pm \mathrm{SD}$ \\
\hline \multicolumn{3}{|l|}{$\overline{\mathrm{ALT}}$} \\
\hline Normal & 1172 & $11.68 \pm 6.38$ \\
\hline Elevated & 177 & $9.13 \pm 5.05$ \\
\hline \multicolumn{3}{|l|}{ AST } \\
\hline Normal & 1319 & $11.36 \pm 6.22$ \\
\hline Elevated & 30 & $10.55 \pm 8.32$ \\
\hline \multicolumn{3}{|l|}{ GGT } \\
\hline Normal & 1196 & $11.34 \pm 6.22$ \\
\hline Elevated & 114 & $11.02 \pm 7.08$ \\
\hline Reduced & 39 & $12.55 \pm 5.36$ \\
\hline \multicolumn{3}{|l|}{ AP } \\
\hline Normal & 1167 & $11.03 \pm 6.27$ \\
\hline Elevated & 7 & $13.98 \pm 7.43$ \\
\hline Reduced & 175 & $13.38 \pm 5.91$ \\
\hline \multicolumn{3}{|c|}{ Triglycerides } \\
\hline Normal & 952 & $12.25 \pm 6.65$ \\
\hline Increased & 397 & $9.19 \pm 4.63$ \\
\hline \multicolumn{3}{|c|}{ Cholesterol } \\
\hline Normal & 500 & $10.98 \pm 6.58$ \\
\hline Increased & 849 & $11.56 \pm 6.09$ \\
\hline \multicolumn{3}{|c|}{ HDL-Cholesterol } \\
\hline Normal & 1050 & $10.22 \pm 5.39$ \\
\hline Increased & 299 & $15.32 \pm 7.46$ \\
\hline \multicolumn{3}{|c|}{ LDL-Cholesterol } \\
\hline Normal & 538 & $11.58 \pm 6.49$ \\
\hline Erhöht & 811 & $11.19 \pm 6.13$ \\
\hline \multicolumn{3}{|c|}{ Random Glucose } \\
\hline Normal & 1305 & $11.32 \pm 6.27$ \\
\hline Elevated & 37 & $11.70 \pm 5.72$ \\
\hline Reduced & 7 & $14.21 \pm 10.16$ \\
\hline \multicolumn{3}{|l|}{ CRP } \\
\hline Normal & 1192 & $11.48 \pm 6.30$ \\
\hline Elevated & 157 & $10.34 \pm 6.03$ \\
\hline \multicolumn{3}{|l|}{ HOMA } \\
\hline Normal & 211 & $10.49 \pm 6.46$ \\
\hline Elevated & 33 & $9.20 \pm 5.66$ \\
\hline
\end{tabular}

$\mathrm{ALT}=$ Alanine aminotransferase, $\mathrm{AP}=$ Alkaline phosphatase, $\mathrm{AST}=$ Aspartate aminotransferase, $C R P=C$-reactive protein, $G G T=\gamma$-glutamyl-transferase, $\mathrm{HDL}=$ High Density Lipoprotein, HOMA = Homeostasis Model Assessment, $\mathrm{LDL}=$ Low Density Lipoprotein Random-Glucose $=$ Glucose independent of meal times; $\mathrm{HOMA}=$ Homeostasis Model Assessment, $\mathrm{SD}=$ standard deviation.

Multivariate analysis

Multivariate analysis demonstrated a negative correlation between the adiponectin concentration and the factors male sex, hepatic steatosis, BMI, metabolic syndrome
Table 3 Correlation coefficient ( $r$ ) between the adiponectin concentration and different laboratory parameters, and BMI

\begin{tabular}{lcc}
\hline & $\mathbf{r}$ & $\mathbf{p}$ \\
\hline ALT & -0.325 & $<0.0001$ \\
AST & -0.173 & $<0.0001$ \\
GGT & -0.311 & $<0.0001$ \\
AP & -0.176 & $<0.0001$ \\
Cholesterol & 0.062 & 0.0235 \\
LDL-Cholesterol & -0.050 & 0.0675 \\
HDL-Cholesterol & 0.521 & $<0.0001$ \\
Triglycerides & -0.310 & $<0.0001$ \\
Random blood glucose & -0.040 & 0.1390 \\
HOMA & -0.103 & 0.1080 \\
CRP & -0.068 & 0.0128 \\
BMI & -0.292 & $<0.0001$
\end{tabular}

$\mathrm{ALT}=$ Alanine aminotransferase, $\mathrm{AP}=$ Alkaline phosphatase, $\mathrm{AST}=$ Aspartate aminotransferase, $\mathrm{BMI}=$ Body-Mass Index, $\mathrm{CRP}=\mathrm{C}$-Reactive Protein, GGT $=\gamma^{-}$ glutamyl-transferase, $\mathrm{HDL}=$ High Density Lipoprotein, $\mathrm{HOMA}=$ Homeostasis Model Assessment, LDL $=$ Low Density Lipoprotein Random-Glucose $=$ Glucose independent of meal times; $\mathrm{HOMA}=$ Homeostasis Model Assessment, $\mathrm{SD}=$ standard deviation; Random glucose $=$ Glucose independent of time of day.

and tobacco smoking. By comparison, age correlated positively with the adiponectin concentration. While HDLcholesterol exhibited a positive correlation with adiponectin, the correlation with CRP was negative (Table 4).

\section{Discussion}

The present study examined the largest collective of healthy subjects assessed to date for an association between sonographically diagnosed hepatic steatosis and plasma adiponectin concentrations. Sonographic evidence

Table 4 Association of the adiponectin concentration with various parameters in the multivariate regression analysis

\begin{tabular}{lcc}
\hline & $\mathbf{b}$ & $\mathbf{p}$ \\
\hline Male sex & -0.318 & $<.0001$ \\
Hepatic steatosis & -0.064 & 0.0475 \\
BMI & -0.010 & 0.0011 \\
Age & 0.004 & $<.0001$ \\
Triglycerides & -0.024 & 0.1242 \\
HDL Cholesterol & 0.356 & $<.0001$ \\
CRP & -0.004 & 0.0434 \\
Metabolic syndrome & -0.128 & 0.0434 \\
Tobacco smoking & -0.065 & 0.0117 \\
Alcohol consumption $(\mathbf{0 - 2 0} \mathbf{g} / \mathbf{d})$ & 0.052 & 0.0327 \\
Alcohol consumption $(\mathbf{2 0 - 4 0} \mathbf{g} / \mathbf{d})$ & 0.093 & 0.0380 \\
\hline
\end{tabular}

$\mathrm{BMI}=$ Body-mass index, $\mathrm{CRP}=\mathrm{C}$-reaktives Protein, HDL = High-Density-Lipoprotein. 
of hepatic steatosis was documented in $24.7 \%$ of subjects. The multivariate analysis of our data shows a negative correlation between adiponectin and hepatic steatosis. Breaking down study subjects according to sonographically determined hepatic fat content into groups with grade 0,1 and $2 / 3$ steatosis, it was observed that adiponectin concentrations decline inversely to the degree of steatosis.

This observation corresponds to findings of Pisto et al. in which an increase in hepatic fat content, estimated by sonographic assessment of brightness into levels 0,1 and 2, was associated with a decrease in adiponectin concentrations [15]. The results of that study and ours are in good agreement even though the earlier study measured comparatively higher adiponectin concentrations. These differences in adiponectin concentrations may possibly be due to the different age distribution of the two study collectives as since the concentration of adiponectin in the blood increases with age [16].

In our study collective, the mean adiponectin concentration was significantly higher in women than in men. This known difference between the sexes emerges at puberty and efforts have been made to explain it on the basis of differences in androgen levels [16,17]. Experimental studies, however, have failed to demonstrate a direct influence of androgens on adiponectin concentrations. It has been postulated that the sex hormones regulate as yet unknown factors that, in turn, affect the adiponectin concentration [18].

In our study collective, BMI correlates negatively with the adiponectin concentration. These results correspond with those of earlier studies [19]. However, it has also been shown that adiponectin is not associated with the BMI or subcutaneous adipose tissue but correlates significantly and negatively with the mass of visceral adipose tissue [20]. It was furthermore shown that adiponectin concentrations correlated negatively with the mass of visceral fat but positively with the mass of subcutaneous fat [21]. Contradictory study findings regarding the association between adiponectin and BMI are possibly the result of the different composition of the respective study collectives with respect to the degree of overweight and the relative proportions of subcutaneous and visceral adipose tissue [21].

A total of $61.2 \%$ of the subjects in our study population were physically active (by self-report). Those who engaged in physical exercise showed higher mean adiponectin concentrations than did subjects who did not report being physically active. Multivariate analysis, however, failed to demonstrate a statistically significant difference in adiponectin levels between these groups. It is possible that the intensity of physical exercise was too low or the difference in physical activity between the groups was too small. A review of the literature reveals that participation in a physical exercise program is associated with an increase in adiponectin concentrations in the blood [22,23] and that the fat content and histological signs of inflammation in the liver are reduced [24]. The association between adiponectin and cardiovascular risk factors and NAFLD were described. There was a correlation between adiponectin and steatosis hepatis, and there was a correlation between adiponectin and hypertension. The association between fatty liver and hypertension is well known [25]. Further NAFLD with or without increased ALT levels is associated with progression of blood pressure over time and incident hypertension [26,27]. In our study out of 1349 healthy subjects only 80 subjects had NAFLD. Because of the low portion of subjects with hypertension the relationship between hypertension and hepatic steatosis was not analyzed in detail.

In our study, adiponectin concentrations correlated negatively with triglycerides and positively with HDLcholesterol. These observations correspond to the findings of other studies [28]. The action of adiponectin on triglyceride concentrations is ascribed to an increase in fatty acid oxidation via sequential activation of AMPK, p38 MAPK and PPAR- $\alpha$ [29]. A direct action of adiponectin on the catabolism of apoprotein A-I explains the positive correlation between adiponectin and HDLcholesterol [30].

Only $3.9 \%$ of subjects participating in the present study fulfilled the minimum number of criteria required for diagnosing metabolic syndrome. The low prevalence of metabolic syndrome is most likely due to the fact that diabetics, who very frequently suffer from metabolic syndrome, were not included in the study [31].

Adiponectin was negatively associated with plasma CRP concentrations. This association confirms observations reported by other authors [28]. Anti-inflammatory properties have also been described for adiponectin and this may be important in the progression of NAFL to NASH $[32,33]$. Evidence from animal experiments suggests that adiponectin attenuates signs of inflammation and may protect against the development of NASH [34]. It has recently been shown in one prospective study and in another longitudinal study that a high adiponectin concentration protects against development of metabolic syndrome $[35,36]$.

In the present study, multivariate analysis showed a significant positive association between adiponectin and moderate alcohol consumption. Earlier randomized cross-over and intervention studies had also reported that moderate alcohol consumption was associated with an increase in adiponectin levels $[37,38]$. In contrast to the findings of studies conducted in Europe, cross-sectional studies from Japan found a negative association between adiponectin and alcohol consumption [39]. These divergent findings may have an ethnic basis or related to subjects' environment. 
In our study, adiponectin concentrations were lower in those subjects classified as tobacco smokers than in non-smokers. This corresponds to the finding that, in non-smokers, acute exposition to tobacco smoke results in a decline in adiponectin levels within 12 hours and that smokers who abstain from smoking exhibit an increase in adiponectin concentrations within two months $[40,41]$. The reduced adiponectin level in smokers may be explained by an inhibitory effect of nicotine on the expression of adiponectin from fat cells [40]. The role of genetic background in the association between adiponectin and fatty liver was not addressed in this study. However, it is known from the literature that adiponectin gene rs266729 polymorphism increases the risk of NAFLD [42]. Also the transcription factor sterol regulatory element-binding protein-1 c (SREBP-1c) may contribute to the development of NAFLD. The SREBP-1c gene rs11868035 polymorphism is associated with a high risk of NAFLD [43]. Further genetic variants in the Patatin like phospholipase-3 (PNPLA3) gene are associated with increased risk of nonalcoholic fatty liver disease $[44,45]$. PNPLA3 rs738409 (I148M) genotypes may represent a genetic determinant of serum adiponectin concentrations and may be involved in mediating the susceptibility of liver steatosis [46].

Hypertension and NAFLD both are components of the metabolic syndrome and are associated with low levels of adiponectin. Increased expression of adiponectin or administration of recombinant adiponectin corrects hypertension and NAFLD. This implies a therapeutic potential of adiponectin [47]. Further low levels of adiponectin are found in subjects with diabetes and coronary artery disease [48]. Raising adiponectin levels or enhancing activity of adiponectin receptors may attenuate the components of the metabolic syndrome and may improve the management of diabetes and of cardiovascular diseases [49].

The main strength of the present study is that it examined a healthy population under normal domestic conditions using standardized methods. One weakness is that only $60 \%$ of the selected population actually participated in the study. This is due in part to the exclusion of subjects with liver diseases and diabetes mellitus, as well as subjects with incomplete documentation. Other drawbacks were that the study is a cross-sectional study with singular observations and that collection of personal data were based on questionnaires. The study was aimed at the association between adiponectin and NAFLD. In the population the portion of participants with hypertension and metabolic syndrome were relatively low. Larger studies with patients with the metabolic syndrome or with hypertension are necessary to confirm the observations made in this population based study. Another weakness of the present study is that the genetic background of the association of adiponectin with steatosis and hypertension is not addressed. The relationship between normotensive and hypertensive blood pressure values and adiponectin concentrations was established in our study. Previously, the glycoprotein PI(A2) allele was identified as an risk factor for stroke in high-risk hypertensive patients [50]. In the present study, we did not investigate glycoprotein IIIa PI(A1/A2) polymorphism in subjects with hypertension. It is possible that the PI (A1/A2) polymorphism is important for development of both hypertension and NAFLD. In patients with CAD, for instance, the presence of the PIA2 allele was associated with a higher risk of cardiovascular events, while, in hypertensive patients with cerebrovascular events, the PIA2 allele increased the risk of stroke [51]. As hypertension is the most frequent component of the metabolic syndrome, the genetics underlying the regulation of blood pressure may be crucial for the development of cardiovascular and cerebrovascular events. Understanding the underlying pathogenetic mechanisms of hypertension may lead to more effective strategies of treatment. Recently, it has been shown that the CaMKIIV gene is involved in regulation of vascular tone and blood pressure. In hypertensive patients, a CaMKIV polymorphism identifies a subset of patients with higher blood pressure values [52]. It may be assumed that the CaMKIV gene deletion not only induces hypertension and cardiovascular disease but also NAFLD. Further limitations of the study include the fact that liver biopsies were not performed to confirm the sonographic diagnosis of NAFLD and data on alcohol and nicotine use, as well as physical activity, were self-reported by study subjects. In addition, for logistical reasons, blood samples were obtained throughout the day meaning that dietary parameters should be considered critically. In this respect limitation is related to the definition of the metabolic syndrome, that divergent from the NCEP ATP III definition, random blood glucose instead of fasting blood glucose was used as one out of three criteria required.

\section{Conclusion}

The present study investigated factors associated with adiponectin in a collective of healthy subjects examined by means of diagnostic ultrasound.

The numerical differences in the variables influencing adiponectin returned in the descriptive analysis were confirmed at bivariate analysis for BMI, ALT, AST, GGT, AP, total and HDL cholesterol, triglycerides, CRP, arterial blood pressure, metabolic syndrome, nicotine use and alcohol consumption.

Male sex, BMI, triglycerides, CRP, tobacco smoking, metabolic syndrome and non-alcoholic fatty liver correlate negatively with adiponectin concentrations. There was a positive association between adiponectin concentrations 
and age, moderate alcohol consumption and plasma HDLcholesterol levels. These findings underscore the importance of adiponectin as a biomarker for cardiometabolic risk factors and as an indicator for the severity of non-alcoholic fatty liver.

\section{Methods Collective}

Four-thousand persons were selected randomly from the registered population of a southern German city (total population, 12,475). Of these, a total of 2,445 persons participated in the study. Subjects completed a standardized questionnaire regarding personal data, lifestyle habits and medical history. Subjects underwent ultrasound examination to determine the fat content of the liver [53]. Subjects with history of liver diseases, those treated with antidiabetic agents, and those with incomplete data were excluded from the study (Figure 1). Of the remaining 1,349 subjects, $54.3 \%$ were women.

The study was conducted in conformity with the principles of the Helsinki Declaration and Good Clinical Practice recommendations and was approved by the Ethics Commission of the State Medical Council of Baden-Württemberg (No. 133-02, 24 September 2002). All study participants provided their informed written consent.

\section{Questionnaire}

Each subject received a questionnaire that was completed under the supervision of a trained interviewer. Subjects provided information on their date of birth, sex, body height, body weight, social history, medical history, alcohol consumption, smoking habits and physical activity. In order to validate the results multiple crosschecked questions on the same topic were addressed to the participants. The interview was partially based on validated instruments from other, predominantly

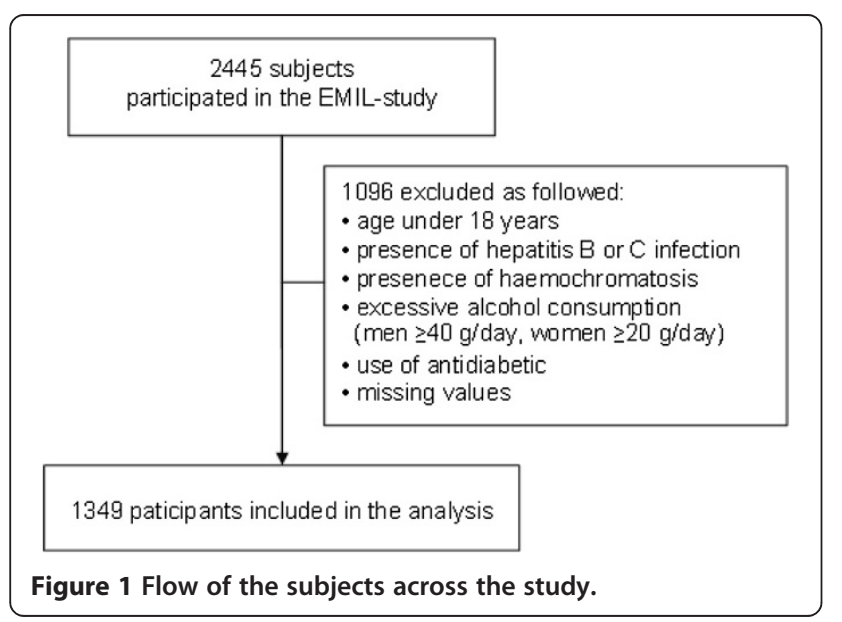

cardiovascular, studies (i. e. alcohol questions from the MONICA Study). Further details on the questionnaire has been published in a previous work of the EMIL-study group [53].

\section{Laboratory studies}

Blood samples for laboratory examinations were obtained by means of phlebotomy of a cubital vein. Routine laboratory testing was performed in the Department of Clinical Chemistry of the University Hospital of Ulm using the Dimension XL unit (Dade Behring Inc, Newark, DE, USA) in accordance with guidelines of the International Federation of Clinical Chemistry and Laboratory Medicine (IFCC). Adiponectin concentrations were determined radioimmunologically using the Human Adiponectin RIA Kit (Catalog HADP-61HK, Biotrend Chemikalien $\mathrm{GmbH}$, Cologne, Germany). LDL cholesterol concentrations were calculated using the Friedewald formula. The diagnosis of metabolic syndrome was made in accordance with the National Cholesterol Education Program Adult Treatment Panel III criteria (NCEP-ATP III) [54] with the exception that random blood glucose levels were substituted for the fasting glucose concentration required by NCEP-ATP III.

\section{Ultrasound}

All subjects underwent ultrasound examination of the liver. Examinations were performed by specially trained examiners using four identical HDI 5000 ultrasound scanners (ATL Ultrasound, Philips Medical Systems, Bothell, WA, USA) under the supervision of an experienced sonographer. Findings were documented using a standardized recording form. Based on a sonographic comparison of the hepatic and renal parenchyma, assessment of dorsal echo attenuation by the liver, the visualization of the diaphragm and the hepatic vessels, the degree of hepatic steatosis was classified as "none" (grade 0 ), or as "mild" (grade 1), "moderate" (grade 2), or "severe" (grade 3) fatty liver disease [55]. The sonographic grading of hepatic steatosis into severity grades 0 to 3 has been shown to be clinically reliable and useful [56].

\section{Statistical analysis}

Statistical calculations were performed using the SAS statistical software package (version 9.2; SAS Institute, Cary, NC, USA). Constant laboratory values were divided into classes with respect to their reference ranges. Historical data were divided according to reasonable criteria. Data were first analyzed descriptively. Categorical variables were represented with absolute and relative frequencies. Mean and standard deviation were determined for constant variables.

The correlation of adiponectin with quantitative variables was calculated using the Spearman rank correlation. 
The Wilcoxon rank sum test or the Kruskal-Willis test were used for qualitative variables. Multivariate linear regression was used to test the influence of individual parameters on adiponectin concentrations. Adiponectin concentrations were log transformed in order to achieve a normal distribution. All tests were two-tailed. Statistical significance was established at $\alpha=5 \%$.

\section{Abbreviations}

ALT: Alanine aminotransferase; AMPK: Activated protein kinase; AP: Alkaline phosphatase; AST: Aspartate aminotransferase; BMI: Body-mass index; CAD: Coronary artery disease; CRP: C-reactive protein; GGT: $y$-glutamyltransferase; HCC: Hepatocellular carcinoma; HDL: High-density lipoprotein; HOMA: Homeostatic model assessment; LDL: Low-density lipoprotein; MAPK: Mitogen-activated protein kinase; NAFL: Non-alcohol fatty liver; NAFLD: Non-alcoholic fatty liver disease; NASH: Non-alcoholic steatohepatitis; NCEP-ATP III: National cholesterol education program adult treatment panel III; PPAR: Peroxisome proliferator-activated receptor; SD: Standard deviation.

\section{Competing interests}

The authors declare that they have no competing interests.

\section{Authors' contribution}

MFM, SG, SO, MMH, WKoe, Al, BOB, WK and ASA were involved in the design and conduct of the study. SG, SO, MMH, WKoe, Al, BOB, and TG collected and analysed the data. MFM, SG, SO, MMH, RAM, WK and ASA were involved in data interpretation and manuscript writing. All authors read and approved the final version.

\section{Acknowledgements}

Members of the EMIL-Study-Group (in alphabetical order)

Adler G, Armsen A, Banzhaf H-M, Bauerdick M, Bertling U, Boehm BO, Brandner BO, Brockmann SO, Deckert M, Dingler C, Eggink S, Fuchs $M$, Gaus W, Goussis H, Gruenert A, Haenle MM, Hampl W, Haug C, Hay B, Huetter M-L, Imhof A, Kern P, Kimmig P, Kirch A, Klass D, Koenig W, Kratzer W, Kron M, Manfras B, Meitinger K, Mertens T, Oehme R, Pfaff G, Piechotowski I, Reuter S, Romig T, von Schmiesing AFA, Steinbach G, Tourbier M, Voegtle A, Walcher T, Wolff S.

\begin{abstract}
Author details
${ }^{1}$ Institute of Epidemiology and Medical Biometry, Albert-Einstein-Allee 41, Ulm 89081, Germany. ${ }^{2}$ Department of Internal Medicine I, University Hospital Ulm, Albert-Einstein-Allee 23, Ulm 89081, Germany. ${ }^{3}$ Department of Internal Medicine II, University Hospital UIm, Albert-Einstein-Allee 23, Ulm 89081, Germany. ${ }^{4}$ Department of Diagnostic and Interventional Radiology, University Medical Center Ulm, Albert-Einstein-Allee 23, Ulm 89081, Germany. ${ }^{5}$ Louis Stokes Cleveland Department of Veterans Affairs Medical Center, 10700 East Boulevard, Cleveland, Ohio 44106, USA.
\end{abstract}

Received: 30 July 2013 Accepted: 31 March 2014

Published: 3 April 2014

\section{References}

1. Sanyal AJ: NASH a global health problem. Hepatol Res 2011, 41:670-674.

2. Tannapfel A, Denk H, Dienes HP, Langner $C$, Schirmacher $P$, Trauner M, Flott-Rahmel B: Histopathological diagnosis of non-alcoholic and alcoholic fatty liver disease. Virchows Arch 2011, 458:511-523.

3. Petta S, Muratore C, Craxi A: Non-alcoholic fatty liver disease pathogenesis: the present and the future. Dig Liver Dis 2009, 41:615-625.

4. Farrell GC, Larter CZ: Nonalcoholic fatty liver disease: from steatosis to cirrhosis. Hepatology 2006, 43(2 Suppl 1):99-112.

5. Starley BQ, Calcagno CJ, Harrison SA: Nonalcoholic fatty liver disease and hepatocellular carcinoma: a weighty connection. Hepatology 2010, 51:1820-1832.

6. Park SK, Seo MH, Shin HC, Ryoo JH: The clinical availability of non-alcoholic fatty liver disease as an early predictor of type 2 diabetes mellitus in korean men: 5-years' prospective cohort study. Hepatology 2013, 57:1378-1383.

7. Lee SP: Non-alcoholic fatty liver disease, a marker of subclinical atherosclerosis applicable only to metabolic syndrome?: Time to organize the connection between metabolism and atherosclerosis. J Cardiovasc Ultrasound 2012, 20:124-125.

8. Buechler C, Wanninger J, Neumeier M: Adiponectin, a key adipokine in obesity related liver diseases. World I Gastroenterol 2011, 17:2801-2811.

9. Marchesini G, Bugianesi E, Forlani G, Cerrelli F, Lenzi M, Manini R, Natale S, Vanni E, Villanova N, Melchionda N, Rizzetto M: Nonalcoholic fatty liver, steatohepatitis, and the metabolic syndrome. Hepatology 2003, 37:917-923.

10. Postic C, Girard J: Contribution of de novo fatty acid synthesis to hepatic steatosis and insulin resistance: lessons from genetically engeneered mice. J Clin Invest 2008, 118:829-838.

11. Wree A, Kahraman A, Gerken G, Canbay A: Obesity affects the liver the link between adipocytes and hepatocytes. Digestion 2011, 83:124-133

12. Sanjari M, Khodashahi M, Gholamhoseinian A, Shokooki M: Association of adiponectin and metabolic syndrome in women. J Res Med Sci 2011, 16:1532-40.

13. Gokulakrishnan $\mathrm{K}$, Anjana RM, Indulekha $\mathrm{K}$, Anuradha S, Mohan V: Association of hypoadiponectinemia with non-alcoholic fatty liver disease in urban south Indians-(CURES - 81). Indian J Med Res 2010, 132:271-277.

14. Mendez-Sanchez N, Chavez-Tapia NC, Villa AR, Sanchez-Lara K, Zamona-Valdes D, Ramos MH, Uribe M: Adiponectin as a protective factor in hepatic steatosis. World J Gastroenterol 2005, 11:1737-1741.

15. Pisto $\mathrm{P}$, Ukkola $\mathrm{O}$, Santaniemi M, Kesäniemi YA: Plasma adiponectin an independent indicator of liver fat accumulation. Metabolism 2011, 60:1515-1520.

16. Bugianesi E, Pagotto U, Manini R, Vanni E, Gastaldelli A, de lasio R, Gentilcore E, Natale S, Cassader M, Rizzetto M, Pasquali R, Marchesini G: Plasma adiponectin in nonalcoholic fatty liver is related to hepatic insulin resistance and hepatic fat content, not to liver disease severity. J Clin Endocrinol Metab 2005, 90:3498-3504.

17. Böttner $A$, Kratsch J, Müller $G$, Kapellen $T M$, Blüher $S$, Keller E, Blüher $M$, Kiess W: Gender differences of adiponectin levels develop during the progression of puberty and are relared to serum androgen levels. J Clin Endocrinol Metab 2004, 89:4053-4062.

18. Horenburg S, Fischer-Posovszky P, Debatin KM, Wabitsch M: Influence of sex hormones on adiponectin expression in human adipocytes. Horm Metab Res 2008, 40:779-786.

19. Mohammadzadeh G, Zarghami N: Hypoadiponectinemia in obese subjects with type II diabetes: A close association with central obesity indices. J Res Med Sci 2011, 16:713-723.

20. Kishida K, Kim KK, Funahashi T, Matsuzawa Y, Kang HC, Shimomura I: Relationships between circulating adiponectin levels and fat distribution in obese subjects. J Atheroscler Thromb 2011, 18:592-595.

21. Hanley AJ, Bowden D, Wagenknecht LE, Balasubramanyam A, Langfeld C, Saad MF, Rotter JI, Guo X, Chen YD, Bryer-Ash M, Norris JM, Haffner SM: Association of adiponectin with body fat distribution and insulin sensitivity in nondiabetic Hispanics and African-Americans. J Clin Endocrinol Metab 2007, 92:2665-2671.

22. Mujumdar PP, Duerksen-Hughes PJ, Firek AF, Hessinger DA: Long-term, progressive, aerobic training increases adiponectin in middle-aged, overweight, untrained males and females. Scand J Clin Lab Invest 2011, 71:101-107.

23. Kelly KR, Blaszczak A, Haus JM, Patrick-Melin A, Fealy CE, Solomon TP, Kalinski MI, Kirwan JP: A 7-d exercise program increases high-molecular weight adiponectin in obese adults. Med Sci Sports Exerc 2012, 44:69-74.

24. Thoma C, Day CP, Trenell MI: Lifestyle interventions for the treatment of non-alcoholic fatty liver disease in adults: a systematic review. J Hepatol 2012, 56:255-266.

25. Brookes MJ, Igbal TH, Cooper BT: Hypertension and hepatic steatosis. Curr Hypetens Rep 2008, 10:182-187.

26. Lau K, Lorbeer R, Haring R, Schmidt CO, Wallaschofski H, Nauck M, John U, Baumeister SE, Völzke H: The association between fatty liver disease and blood pressure in a population-based prospective longitudinal study. J Hypertens 2010, 28:1829-1835.

27. Lopez-Suarez A, Guerrero JM, Elvirs-Gonzalez J, Beltran-Robles M, Canas-Hormigo F, Bascunana-Quirell A: Nonalcoholic fatty liver disease is associated with blood pressure in hypertensive and nonhypertensive individuals from the general population with normal levels of alanine aminotransferase. Eur J Gastrenterol Hepatol 2011, 23:1011-1017.

28. Kantartzis K, Rittig K, Balletshofer B, Machann J, Schick F, Porubska K, Fritsche A, Häring HU, Stefan N: The relationships of plasma adiponectin with a 
favorable lipid profile, decreased inflammation, and less ectopic fat accumulation depend on adiposity. Clin Chem 2006, 52:1934-1942.

29. Yamauchi T, Kamon J, Ito Y, Suchida A, Yokomizo T, Kita S, Sugiyama T, Miyagishi M, Hara K, Tsunoda M, Murakami K, Ohteki T, Uchida S, Takekawa S, Waki H, Tsuno NH, Shibata Y, Terauchi Y, Froguel P, Tobe K, Koyasu S, Taira K, Kitamura T, Shimizu T, Nagai R, Kadowaki T: Cloning of adiponectin receptors that mediate antidiabetic metabolic effects. Nature 2003, 423:762-769.

30. Verges B, Petit JM, Duvillard L, Dautin G, Florentin E, Galland F, Gambert P. Adiponectin is an important determinant of apoA-I catabolism. Arterioscler Thromb Vasc Biol 2006, 26:1364-1369.

31. Lin SX, Pi-Sunyer EX: Prevalence of the metabolic syndrome among US middle-aged and older adults with and without diabetes - a prliminary analysis of the NHANES 1999-2002 data. Ethn Dis 2007, 17:35-39.

32. Ohashi K, Ouchi N, Matszawa Y: Anti-inflammatory and anti-atherogenic properties of adiponectin. Biochimie 2012, 94:2137-2142

33. Moschen AR, Wieser $\mathrm{V}$, Tilg $\mathrm{H}$ : Adiponectin: key player in the adipose tissue-liver crosstalk. Curr Med Chem 2012, 19:5467.

34. Xu A, Wang Y, Keshaw H, Xu L, Lam KS, Cooper GJ: The fat-derived hormone adiponectin alleviates alcoholic and non-alcoholic fatty liver disease in mice. J Clin Invest 2003, 112:91-100.

35. Kim JY, Ahn SV, Yoon JH, Koh SB, Yoon J, Yoo BS, Lee SH, Park JK, Choe KH, Guallar E: Prospective study of serum adiponectin and incident metabolic syndrome: the ARIRANG Study. Diabetes Care 2012, 36:1547-1553.

36. Juonala M, Saarikoski LA, Vikari JS, Oikonen M, Lehtimäki T, Lyytikäinen LP, Huupponen R, Magnussen CG, Koskinen J, Laitinen T, Taittonen L, Kähönen M, Kivimäki M, Raitakari OT: A longitudinal analysis on associations of adiponectin levels with metabolic syndrome and carotid artery intima-media thickness. The Cardivascular Risk in Young Finns Study. Atherosclerosis 2011, 217:234-239.

37. Joosten MM, Beulens JW, Kersten S, Hendriks HF: Moderate alcohol consumption increases insulin sensitivity and ADIPOQ expression in postmenopausal women: a randomised, crossover trial. Diabetologia 2008, 51:1375-1381.

38. Imhof A, Plamper I, Maier S, Rischler G, Koenig W: Effect of drinking on adiponectin in healthy men and women: a randomized intervention study of water, ethanol, red wine, and beer with or without alcohol. Diabetes Care 2009, 32:1101-1103.

39. Nishise $Y$, Saito T, Makino N, Okumoto K, Ito Jl, Watanabe H, Saito K, Togashi H, Ikeda C, Kubota I, Daimon M, Kato T, Fukao A, Kawata S: Relationship between alcohol consumption and serum adiponectin levels: the Takahata study - a cross-sectional study of a healthy Japanese population. J Clin Endocrinol Metab 2010, 95:3828-3835.

40. Iwashima Y, Katsuya T, Ishikawa K, Kida I, Ohishi M, Horio T, Ouchi N, Ohashi K, Kihara S, Funahashi T, Rakugi H, Ogihara T: Association of hypoadiponectinemia with smoking habit in men. Hypertension 2005, 45:1094-1100

41. Tsai JS, Guo FR, Chen SC, Lue BH, Lee LT, Huang KC, Chen CY, Hung SH, Chuang LM, Chen CY: Changes of serum adiponectin and soluable intercellular adhesion molecule-1 concentrations after smoking cessation. Clin Chem Lab Med 2012, 50:1063-1069.

42. Hashemi M, Hanafi Bojd H, Eskandari Nasab E, Bahari A, Hashemzehi NA, Shafieipour S, Narouie B, Taheri M, Ghavami S: Association of adiponectin rs266729 gene polymorphism with nonalcoholic fatty liver disease. Hepat Mon 2013, 13:e9527.

43. Musso G, Bo S, Cassader M, De Michieli F, Gambino R: Impact of sterol regulatory element-binding factor-1c polymorphism on incidence of nonalcoholic fatty liver disease and on severity of liver disease and of glucose and lipid dysmetabolism. Am J Clin Nutr 2013, 98:895-906.

44. Peng XE, Wu YL, Lin SW, Lu QQ, Hu ZJ, Lin X: Genetic variants in PNPLA3 and risk of non-alcoholic fatty liver disease. Plos One 2012, 7:e50256

45. Lin YC, Chang PF, Hu FC, Yang WS, Chang MH, Ni YH: A common variant in the PNPLA3 gene is a risk factor for non-alcoholic fatty liver disease in obese Taiwanese children. J Pediatr 2011, 158:740-744.

46. Valenti L, Rametta R, Ruscica M, Dongiovanni P, Steffani L, Motta BM, Canavesi E, Fracanzani AL, Mozzi E, Roviaro G, Magni P, Fargion S: The I148 PNPLA3 polymorphism influences serum adiponectin in patients with fatty liver and healthy controls. BMC Gastroenterol 2012, 12:111.

47. Padmalayam I, Suto M: Role of adiponectin in the metabolic syndrome: current perspectives on its modulation as a treatment strategy. Curr Pharm Des 2013, 19:5755-5763.
48. Whitehead JP, Richards AA, Hickman IJ, Macdonald GA, Prins JB: Adiponectin-a key adipokine in the metabolic syndrome. Diabetes Obes Metab 2006, 8:264-280

49. Yamauchi T, Kadowaki T: Physiological and pathophysiological roles of adiponectin and adiponectin receptors in the integrated regulation of metabolic and cardiovascular diseases. Int J Obes 2008, 32(Suppl 7):13-18.

50. Lanni F, Santulli G, Izzo R, Rubattu S, Zanda B, Volpe M, laccarino G, Trimarco B: The $\mathrm{PI}(\mathrm{A} 1 / \mathrm{A} 2)$ polymorphism of glycoprotein Illa and cerebrovascular events in hypertension: Increased risk of ischemic stroke in high-risk patients. J Hypertens 2007, 25:551-556.

51. Galasso G, Santulli G, Piscione F, De Rosa R, Trimarco V, Piccolo R, Cassese S, laccarino G, Trimarco B, Chiariello M: The GPIIla PIA2 polymorphism is associated with an increased risk of cardiovascular adverse events. BMC Cardiovasc Disord 2010, 10:41.

52. Santulli G, Cipoletta E, Sorriento D, Del Giudice C, Anastasio A, Monaco S, Maione AS, Condorelli G, Puca A, Trimarco B, Illario M, laccarino G: CaMK4 gene deletion induces hypertension. J Am Heart Assoc 2012, 1:e001081.

53. Haenle MM, Brockmann SO, Kron M, Bertling U, Mason RA, Steinbach G, Boehm BO, Koenig W, Kern P, Piechotowski I, Kratzer W, EMIL-Study group: Overweight, physical activity, tobacco and alcohol consumption in a cross-sectional random sample of German adults. BMC Public Health 2006, 6:233.

54. Alberti KG, Eckel RH, Grundy SM, Zimmet PZ, Cleeman Jl, Donato KA Fruchart JC, James WP, Loria CM, Smith SC Jr, International Diabetes Federation Task Force on Epidemiology and Prevention; Hational Heart, Lung, and Blood Institute; American Heart Association; World Heart Federation; International Atherosclerosis Society; International Association for the Study of Obesity: Harmonizing the metabolic syndrome: a joint interim statement of the International Diabetes Federation Task Force on Epidemiology and Prevention; National Heart, Lung, and Blood Institute; American Heart Association; World Heart Federation; International Atherosclerosis Society; and International Association for the Study of Obesity. Circulation 2009, 120:1640-1645.

55. Sanyal AJ: AGA technical review on nonalcoholic fatty liver disease. Gastroenterolgy 2002, 123:1705-1725.

56. Kratzer W, Akinli AS, Bommer M, Arnold F, Eggink S, Imhof A, Mason RA, Klaus J, Schuler A, Boehm BO, Haenle MM: Prevalence and risk factors of focal sparing in hepatic steatosis. Ultraschall Med 2010, 31:37-42.

doi:10.1186/1756-0500-7-207

Cite this article as: Flechtner-Mors et al:: Association of adiponectin with hepatic steatosis: a study of 1,349 subjects in a random population sample. BMC Research Notes 2014 7:207.

\section{Submit your next manuscript to BioMed Central and take full advantage of:}

- Convenient online submission

- Thorough peer review

- No space constraints or color figure charges

- Immediate publication on acceptance

- Inclusion in PubMed, CAS, Scopus and Google Scholar

- Research which is freely available for redistribution

Submit your manuscript at www.biomedcentral.com/submit
C) Biomed Central 